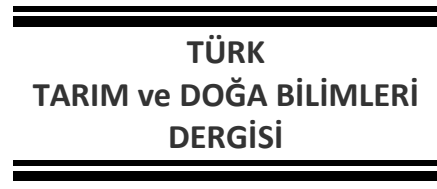

\section{Ardahan'da Yetişen Kediotunun (Valeriana officinalis L.) Antimikrobiyal Ve Antioksidan Potansiyelinin Belirlenmesi}

www.dergipark.gov.tr/turkjans

\author{
Vesile DÜZGÜNER*, Nurcan ERBiL
}

Ardahan Üniversitesi, Sağlık Bilimleri Yüksekokulu, 75000, Ardahan

*Sorumlu yazar: vesileduzguner@ardahan.edu.tr

Geliş Tarihi: 10.12 .2018

Düzeltme Geliş Tarihi: 04.03.2019

Kabul Tarihi: 13.03.2019

\title{
Özet
}

Valerianceae familyasına ait olan kediotu (Valeriana officinalis L.) yerel olarak Avrupa ve Asya'da bulunan çiçekli bir bitkidir ve çoğunlukla uykusuzluk hastalığı ve kaygı bozukluklarının tedavisi için kullanılmaktadır. Bu çalışmada Ardahan yöresinden toplanan kediotunun antioksidan ve antimikrobiyal aktiviteleri incelenmiştir. Kediotunun metanol/ethanol ekstraktlarının antimikrobiyal aktivitesi Pseudomonas aeroginosa (ATCC 9027), Staphylococcus aureus (ATCC 6538), Bacillus megaterium (DSM 32), Escherichia coli, Yarrovia lipolytica, Candida albicans ve Saccharomyces cerevisiae'ya karşı test edilmiştir. Bitkilerin Glutatyon (GSH) düzeyi spektrofotometrik olarak, total oksidan ve antioksidan kapasiteleri (sırasıyla TOK ve TAK) ise ELISA yöntemi ile ölçülmüştür. Kediotunun, bu çalışmada kullanılan test mikroorganizmalarına karşı hafif oranda antibakteriyel aktiviteye sahip olduğu tespit edilmiştir. Metanol ekstraktlarındaki GSH düzeyi etanol ekstraktlarından daha yüksek çıkmıştır. Benzer şekilde total antioksidan kapasite ölçümlerinde methanol ekstraktlarındaki değerler etanol ekstraktlarından fazla saptanmıştır. Sonuç olarak Valeriana officinalis'in yararlı etkilerini belirleyen antibakteriyal ve antioksidatif içeriklerinin etki mekanizması ile ilişkisinin in vitro çalışmalarla desteklenmesi gerektiği kanısına varılmıştır.

Anahtar kelimeler: Antimikrobiyal, Antioksidan, Glutatyon, Oksidatif Stres, Valeriana Officinalis.

\section{Determination of Antioxidative and Antimicrobial Potential of Valerian (Valeriana officinalis L.) Grown in Ardahan Region}

\begin{abstract}
Valerian (Valeriana officinalis L.) that belongs to Valerianceae family is a flowering plant native to Europe, and Asia and it is most commonly used for the treatment of insomnia and anxiety disorders. In this study, the antimicrobial activity and an antioxidant capacity of valerian collected from Ardahan region were investigated. Methanol/ethanol extracts of valerian were tested for antimicrobial activity against Pseudomonas aeroginosa (ATCC 9027), Staphylococcus aureus (ATCC 6538), Bacillus megaterium (DSM 32), Escherichia coli, Yarrovia lipolytica, Candida albicans and Saccharomyces cerevisiae. The measurements of glutathione (GSH) levels were done spectrophotometrically and total oxidant and antioxidant capacity (TOC and TAC, respectively) were performed by ELISA method. Antibacterial activity was found at different rate against test microorganisms used in this study. Additionally, GSH levels were higher in methanolic extracts than ethanolic extracts. Similarly, it was determined that TAC in the methanolic extract was much better than ethanolic extract. In conclusion, it has been concluded that the mechanism of action of antibacterial and antioxidative ingredients that determine beneficial effects of Valeriana officinalis should be supported by in vitro studies.
\end{abstract}

Keywords: Antimicrobial, Antioxidant, Glutathione, Oxidative S tress, Valeriana officinalis. 


\section{Giriş}

Reaktif oksijen türleri (ROS), normal aerobik metabolizmanın istenmeyen metabolik yan ürünleri olarak tüm hücrelerde oluşan yüksek derecede reaktif ve potansiyel olarak zararlı geçici kimyasal türlerdir. Hücreler, çeşitli endojen ROS temizleyici enzimler ve kimyasal bileşikler tarafından ROS kaynaklı hasardan korunur (Halliwell ve Gutteridge, 1990). ROS üreten mekanizmalar ve temizleyici hücre içi sistemler arasındaki dengesizlikten kaynaklanan doku hasarı ('oksidatif stres"), kanser, kalp hastalıkları, Alzheimer ve diyabet gibi çeşitli rahatsızlıkların patogenezinde rol oynamaktadır. Antioksidanlar ise, biyomolekülleri serbest radikallerin neden olduğu saldırılara karşı koruyabilirler. Genel olarak, antioksidanlar sentetik ve doğal olmak üzere iki gruba ayrılır. Doğal antioksidanlar tüm yüksek bitkilerde ve bitkinin tüm kısımlarında (ağaç, ağaç kabuğu, saplar, bakla, yapraklar, meyve, kökler, çiçekler, polenler ve tohumlar) oluşur. Antioksidan aktivite sergileyen tipik bileşikler arasında vitaminler, karotenoidler ve fenolikler bulunur. Son zamanlarda, bu tür serbest radikal kaynaklı doku hasarının azaltılmasında antioksidanlar olarak tıbbi bitkilerin terapötik potansiyeline farmakolojik aktiviteleri, düşük toksisite ve ekonomik canlılık nedeniyle ilgi artmıştır. (Gülçin ve ark., 2002; Arranz ve ark., 2008).

Valerian (Valeriana officinalis L.), özellikle Amerika, Avrupa ve Asya'nın farklı bölgelerinde dağılmış olan yerli bir bitkidir (Hadley ve Petty, 2003).Türkiye'de halk arasında "kediotu" olarak bilinir. Valerian türlerinin hipnotik, sedatif, anksiyolitik, antikonvülsan ve antidepresan gibi birçok tedavi edici özellikleri olduğu bildirilmiştir (Andreatini ve ark., 2002). Valerianaceae familyasından Valeriana officinalis'in kurutulmuş yeraltı kısımları (kökleri ve rizomları) modern bitkisel madde ürünleri, geleneksel sedatifler ve anti-anksiyete ve sindirim formülasyonları hazırlamak için kullanılmaktadır (Letchamo ve ark., 2004).Valerian rizomları, uçucu yağ ve onun seskiterpenoidleri (valerenik asit), epoksi iridoid esterleri, aminoasitler ve alkaloidleri içeren çeşitli bileşikler içermektedir (Neamati ve ark., 2014). Geleneksel tıpta, bu bitkinin çeşitli bitkisel formülasyonlarının hipertansiyon, anjina, çarpıntı, astım, hepatik kolik ve menstrüel krampların tedavisi için kullanılması önerilmiştir (Circosta ve ark., 2007).

V. officinalis 'in bazı bileşenlerinin terapötik etkisinin, antioksidan aktiviteleri ile ilişkili olduğuna inanılmaktadır. Son çalışmalarda $V$. officinalis ekstrelerinin farklı in vitro ve in vivo modellerde antioksidan aktivite gösterdiği bildirilmiştir (Malva ve ark., 2004; Oliveira ve ark., 2009; Sudati ve ark.,
2009; Jugran ve ark., 2015). V. officinalis ekstreleri veya esansiyel yağlarla muamele edildikten sonra insanlarda veya kemirgenlerde hiçbir toksisite bulgusuna rastlanmamıştır (Pereira ve ark., 2009).

Araştırmamızda, valerian bitkisinin etanol / metanol ekstraktlarının antioksidan ve antimikrobiyal aktivitesi değerlendirilerek potansiyel yararlı etkilerinin açıklanması amaçlanmıştır.

\section{Materyal ve Yöntem}

Valerian (Valeriana officinalis L.) örnekleri, 2017 yılının Haziran ayında Ardahan ilinin Posof ilçesi Türkgözü köyünün Gürcistan sınırına yakın bölgesinden (Rakım: 1218 m) toplandı. Örnekler enkazdan arındırılarak, oda sıcaklığında gölgede kurutuldu ve son olarak toz haline getirildi.

\section{Ekstrakt/arın hazırlanması}

$10 \mathrm{~g}$ toz halinde bitki materyali, Soxhlet aparatına yüklendi ve ekstraksiyon, 6 saat boyunca $300 \mathrm{ml}$ metanol (pi: 6.6) ve etanol (pi: 5.2) kullanılarak gerçekleştirildi. Elde edilen karışım, döner buharlaştırıcı (SciLogex RE100-Pro) ile konsantre edildi. Filtre ile sterilize edilen ekstrakt, kullanıma kadar soğutuldu $\left(-18^{\circ} \mathrm{C}\right)$.

\section{Antimikrobiyal aktivitenin belirlenmesi}

Metanol ekstraktlarının antimikrobiyal aktivitesinin belirlenmesinde agar difüzyon yöntemi kullanılırken, valeriandan elde edilen etanol ekstresi için disk difüzyon yöntemi kullanıldı. Bu amaçla 2 Gram (-) (Pseudomonas Aeroginosa ATCC 9027, Escherichia Coli) ve 2 Gram (+) bakteri (Bacillus Megaterium DSM 32, Staphylococcus Aureus ATCC 6538) ve 3 mantar türü (Yarrovia Lipolytica, Candida Albicans, Saccharomyces Cerevisiae) test mikroorganizmaları olarak kullanıldı. $100 \mu$ l etanolik ekstrakt, steril diskler (6 $\mathrm{mm}$ ) tarafından emilirken, steril kuyulara $(6 \mathrm{~mm})$ aynı doz metanolik ekstrakt eklendi. Pozitif kontrol olarak Gentamisin disk kullanıldı. İnhibisyon bölgeleri vernier kaliper ile ölçüldü ve $\mathrm{mm}$ olarak 3 replikasyonun ortalama çapı olarak kaydedildi. Tüm testler üç kez gerçekleştirildi ve ortalamalar ortalandı.

\section{Biyokimyasal analizler}

Glutatyon (GSH) düzeyleri spektrofotometrik yöntemle ölçüldü (Sedlak ve Lindsay, 1968). 5,5 dithiobis-2-nitrobenzoic asit ile örneklerdeki GSH'ın reaksiyonu ile oluşan son ürün $410 \mathrm{~nm}^{\prime}$ de spektrofotometrik olarak okundu. Sonuçlar, mmol / L olarak ifade edildi. Toplam antioksidan kapasite (TAC) ticari ELISA kiti ile belirlendi. Analiz, ABTS ${ }^{\circledR}$ ye (2,2'-Azino-di- [3etilbenztiazolin sülfonat]), bir peroksidaz 
(metmyoglobin) ve $\mathrm{H} 2 \mathrm{O} 2$ ile radikal katyon $\mathrm{ABTS}^{\circledR}$ + 'yı üretmek üzere inkübe edilir. Bu, 600 nm'de ölçülen nispeten sabit mavi-yeşil bir renge sahiptir. Eklenen numunedeki antioksidanlar, bu renk üretiminin konsantrasyonları ile orantılı bir dereceye kadar bastırılmasına neden olur.

Toplam oksidan kapasitesini (TOC) ölçmek için Ticari ELISA kiti kullanıldı. Numunede bulunan oksidantlar demir iyonu-kenetleme kompleksini ferrik iyona okside eder. Oksidasyon reaksiyonu, reaksiyon ortamında bol miktarda bulunan güçlendirici moleküller tarafından uzatılır. Demir iyonu asidik bir ortamda kromojen ile renkli bir kompleks yapar. Renk dansitesi, örneklerde bulunan toplam oksidan molekül miktarı ile ilgilidir. Numunelerin fenolik içeriği, Lister ve Wilson (2001) yöntemi kullanılarak Folin-Ciocalteu reaktifi ile tespit edildi. Bitki ekstraktı (100 $\mu \mathrm{l}) 0.2 \mathrm{ml}$ FolinCiocalteu reaktifi ve $2 \mathrm{ml} \mathrm{H}_{2} \mathrm{O}$ ile karıştırıldı ve 3 dakika oda sıcaklığında inkübe edildi. Karışıma 1 ml\% 20 sodyum karbonat eklendikten sonra, oda sıcaklığında 1 saat inkübasyondan sonra toplam polifenoller belirlendi. Elde edilen mavi rengin absorbansı bir spektrofotometre ile $765 \mathrm{~nm}$ 'de ölçüldü. Kuantifikasyon, standart gallik asit eğrisine göre yapıldı. Bütün tespitler üç kopya halinde gerçekleştirildi $(n=3)$.

\section{istatistik}

İstatistiksel analizler SPSS (Sosyal Bilimler için İstatistik Paketi) bilgisayar programı (versiyon 16.0) kullanılarak gerçekleştirildi. Sonuçlar ortalama \pm SE olarak sunulmuştur. $P<0.05$ değeri anlamlı kabul edildi.

\section{Bulgular ve Tartışma}

GSH düzeylerinin ve toplam fenolik içeriklerin sonuçları Tablo 1'de gösterilmiştir. Valerian ekstraktlarında GSH içeriğinin yüksek olduğu saptanmıştır. Bununla birlikte metanol ekstraktları etanol ekstraktlarından daha fazla GSH içermektedir $(p<0.005)$. Metanol ekstraktlarının total fenolik içeriğiEtanol ekstraktlarından 4 kat daha fazladır $\quad(p<0.001)$.

Tablo 1. Valeriana officinalis GSH ve total fenolik içerik düzeyleri

\begin{tabular}{lcc}
\hline İçerik & Etanol & Metanol \\
\hline GSH (mmol/L) & $465.62 \pm 6.77$ & $662.00 \pm 6.42$ \\
Total fenolik İçerik (mGAE/g dw) & $530 \pm 4.35$ & $2098 \pm 29.14$ \\
\hline
\end{tabular}

Valerian'ın etanol / metanol ekstrelerinin total antioksidan kapasitesi yüksek düzeylere (sırasıyla $4890 \pm 0.0033 ; 5120 \pm 0.0018$ ) sahipken, düşük seviyelerde total oksidan seviyeleri tespit edilmiştir. Bu nedenle oksidatif stres indeksi düşük çıkmıştır

(Tablo

Tablo 2. Total oksidan ve antioksidan kapasite değerleri

\begin{tabular}{lcc}
\hline Kapasite değerleri & Etanol & Metanol \\
\hline Total antioksidan kapasite $(\mu \mathrm{mol} / \mathrm{L})$ & $4890 \pm 0.0033$ & $5120 \pm 0.0018$ \\
Total oksidan kapasite $(\mu \mathrm{mol} / \mathrm{L})$ & $26.67 \pm 5.77$ & $17.78 \pm 6.66$ \\
Oksidatif stres indeksi $(\mu \mathrm{mol} / \mathrm{L})$ & $0.545 \pm 0.002$ & $0.347 \pm 0.0011$ \\
\hline
\end{tabular}

Valerian ekstraktları, bu çalışmada kullanılan test mikroorganizmalarına karşı hafif antibakteriyel etkinlik göstermiştir (Tablo 3). Valerian etanolik ekstraktlarının, test bakterilerine karşı metanolik ekstrakttan iki kat daha yüksek antibakteriyel etki gösterdiği belirlenmiştir. Ancak ekstraktlar, Candida albicans, Saccharomyces cerevisiae ve Yarrowia lipolytica'ya karşı antifungal aktivite göstermemiştir.

Tablo 3.Valeriana officinalis'in antimikrobiyal aktivitesi

\begin{tabular}{lccc}
\hline Bakteri & Etanol $(\mathbf{m m})$ & Metanol $(\mathbf{m m})$ & Gentamicin $(\mathbf{m m})$ \\
\hline Staphylococcus aureus ATCC 6538 & $12.86 \pm 0.65$ & $6.98 \pm 0.09$ & $28.93 \pm 0.82$ \\
Bacillus megaterium DSM 32 & $14.46 \pm 0.54$ & $7.03 \pm 0.40$ & $27.19 \pm 0.50$ \\
Escherichia coli & $14.29 \pm 0.51$ & $7.20 \pm 0.63$ & $25.24 \pm 0.31$ \\
Pseudomonas aeroginosa ATCC 9027 & $14.46 \pm 0.32$ & $7.49 \pm 0.31$ & $24.80 \pm 0.19$ \\
\hline
\end{tabular}

Valeriana officinalis fenolik içeriği ve ekstraktları uzun zamandır geleneksel tıpta uykusuzluk ve anksiyete gibi bazı nöronal hastalıkların tedavisi için kullanılmıştır (Sudative ark., 2009). Kediotu kökünün sulu ekstraktının, herhangi bir yan etkisi olmadan insanda uyku kalitesini iyileştirdiği bildirilmiştir (Müller ve ark., 2012). Valerianaceae'nin diğer cinsi olan izole Valeriana fauriei Briq köklerinden gelen seskiterpenler de antidepresan aktiviteye sahiptir 
(Liu ve ark., 2012). Tardive diskinezi ve diğer nöronal hastalıklarda, dopaminerjik ve kolinerjik sistemler arasında bozulmuş denge, striatonigral GABAerjik nöronların disfonksiyonu, glutamat ile teşvik edilen eksitotoksisite ve serbest radikallerin aşırı üretimi gibi mekanizmaların yer aldığı bildirilmiştir (Andreassen ve Jorgensen, 2000). Kedi otunun merkezi sinir sistemindeki yararlı etkilerinin ise, mekanizması tam olarak ortaya çıkarılmasa da, beyindeki GABA, melatonin, adenosin veya serotonin sistemleri ile etkileşerek ortaya çıkabileceğini düşünülmektedir (Abourashed ve ark., 2004).

Yapılan çalışmada $V$. officinalis'in antimikrobiyal ve antioksidatif potansiyeli değerlendirilmiş ve sonuçlar bu bitkinin antioksidan kapasitesinin ve toplam fenolik içeriğin anlamlı düzeyde yüksek olduğunu göstermiştir. Benzer şekilde, Sudati ve ark. (2009), V. officinalis'in bazı bileşiklerinin fitomedikal özelliklerinin, antioksidan aktivitelerine bağlı olduğuna inanmaktadır. Ayrıca, uykusuzluğun oksidatif streste bir artışla ilişkili olabileceğini ve $V$. officinalis'in bu durumun sonuçlarını iyileştirmek için kullanıldığını düşünmektedirler. $V$. officinalis ekstraktları ile yapılan in vitro model çalışmaları, yüksek düzeyde antioksidan aktiviteye sahip olduğunu göstermiştir (Malva ve ark., 2004; Sudati ve ark., 2009) ve Parkinson hastalığında sitoprotektif bir etkisi olduğu bildirilmiştir (Oliveira ve ark., 2009).

Antioksidan etkinin bitkinin içerdiği fenolik içeriklerin yoğunluğundan kaynaklandığı bilinmektedir. Önceki çalışmalar bu sonuçları desteklemiş ayrıca, $V$. officinalis 'in antioksidatif aktivitelerinden, bileşenlerden biri olan valerianik asidin sorumlu olabileceği tespit edilmiştir (Pereira ve ark., 2009; Wu ve ark., 2009).

Sung ve ark. (2013), enzimatik olmayan glikasyon yoluyla gelişmiş glikasyon son ürünleri oluşturmak için hem in vivo hem de in vitro proteinler ve peptitlerdeki amino asitlerin serbest aminleriyle kolayca reaksiyona giren bir indirgeyici şeker olan D- galaktoz ile yaptıkları uygulamalarda bu etkenin verilmesinin insan yaşlanmasına benzer hayvanlarda yaşlanma sendromları ile sonuçlanabileceği bildirilmiştir. Ancak Valerian ekstraktları ve / veya Valerian fenoliklerinden olan valerenik asit verilmesinin d-gal kaynaklı hafıza fonksiyonu, hücre proliferasyonu, nöroblast farklılaşması ve serum kortikosteron ve lipid peroksidasyon artışını belirgin şekilde iyileştirdiğini tespit etmişlerdir.

Kedi otunun diğer yararlı özellikleri incelendiğinde, Chen ve ark. (2015), Valeriana officinalis tedavisinin İskemi / Reperfüzyon hasarını önemli ölçüde iyileştirdiğini ve kalp atımını desteklediğini göstermiştir. Ayrıca Valeriana officinalis'in malondialdehid (MDA) seviyelerini önemli ölçüde düşürdüğü ve süperoksit dismutaz ve glutatyon peroksidaz aktivitelerini artırdığını bildirmişlerdir. Valeriana officinalis'in ekstraktlarının lipit peroksidasyonuna karşı önemli bir indirgeyici etkiye sahip olduğu gösterilmiştir (Neamati ve ark., 2014).

\section{Sonuç ve Öneriler}

Yapılan çalışma ve kaynaklar, düşük seviyelerde oksidatif stres ve yüksek seviyelerde antioksidan kapasite, glutatyon ve toplam fenolik içeriğin, kedi otunun tedavi edici etki mekanizmasının nedeni olabileceğini düşündürmektedir. Sonuç olarak, kedi otunun koruyucu etki mekanizmalarının belirlenebilmesi için karmaşık ve çeşitli etken maddelere sahip biyoaktivitesinin ve bunun antioksidatif içeriğiyle bağlantılı olup olmadığının daha ileri düzeyde çalışmalarla incelenmesinin uygun olduğu kanısına varılmıştır.

\section{Kaynaklar}

Abourashed, E.A., Koetter, U., Brattstrom, A. 2004. In vitro binding experiments with a valerian, hops and their fixed combination extract (Ze91019) to selected central nervous system receptors. Phytomedicine, 11: 6338.

Andreassen, O.A., Jorgensen, H.A. 2000. Neurotoxicity Associated with Neuroleptic Induced Oral Dyskinesias in rats. Implications for Tardive Dyskinesia? Progress in Neurobiology, 61: 525-41.

Andreatini, R., Sartori, V.A., Seabra, M.L., Leite, J.R. 2002. Effect of valepotriates (valerian extract) in generalized anxiety disorder: A randomized placebo-controlled pilot study. Phytotherapy Research, 16: 650-654.

Arranz, S., Cert, R., Pérez-Jiménez, J., Cert, A., Saura-Calixto, F. 2008. Comparison between free radical scavenging capacity and oxidative stability of nut oils. Food Chemistry, 110: 985-990.

Chen, H.W., Wei, B.J., He, X.H., Liu, Y., Wang, J. 2015. Chemical Components and cardiovascular activities of Valeriana spp. Evidence-Based Complementary and Alternative Medicine, doi:10.1155/2015/947619.

Circosta, C., De Pasquale, R., Samperi, S., Pino, A., Occhiuto, F. 2007. Biological and analytical characterization of two extracts from Valeriana officinalis. Journal of Ethnopharmacology, 112: 361-367. 
Gülçin, I., Oktay, M., Küfrevioglu, Ö.I., Aslan, A. 2002. Determination of Antioxidant Activity of Lichen Cetraria islandica (L). Journal of Ethnopharmacology, 79: 325-329.

Hadley, S., Petry, J.J. 2003. Valerian. American Family Physician, 67: 1755-1758.

Halliwell, B. ve Gutteridge, J.M., 1990. Role of free radicals and catalytic metal ions in human disease: An overview. Methods in Enzimology, 186: 1-85.

Jugran, A.K., Bahukhandi, A., Dhyani, P., Bhatt, I.D., Rawal, R.S., Nandi, S.K., Palni, L.M.S. 2015. The effect of inoculation with mycorrhiza: AM on growth, phenolics, tannins, phenolic composition and antioxidant activity in Valeriana jatamansi Jones. Journal of Soil Science and Plant Nutrition, 15(4): 10351049.

Letchamo, W., Ward, W., Heard, B., Heard, D. 2004. Essential oil of Valeriana officinalis L. Cultivars and their antimicrobial activity as influenced by harvesting time under commercial organic cultivation. Journal of Agricultural Food Chemistry, 52 (12): 39153919.

Lister, E., Wilson, P. 2001. Measurement of Total Phenolics and ABTS Assay for Antioxidant Activity (personel communication). Crop Research Institute Lincoln, New Zealand.

Liu, X.G., Gao, P.Y., Wang, G.S., Song, S.J., Li, L.Z., Li, X., Yao, X.S., Zhang, Z.X. 2012. In vivo antidepressant activity of sesquiterpenes from the roots of Valeriana fauriei Briq. Fitoterapia, 83: 599-603.

Malva, J.O., Santos, S., Macedo, T. 2004. Neuroprotective properties of Valeriana officinalis extracts. Neurotoxicolgical Research, 6: 131-40.

Müller, L.G., Salles, L.A., Stein, A.C., Betti, A.H., Sakamoto, S., Cassel, E., Vargas, R.F., Von Poser, G.L., Rates, S.M.K. 2012. Antidepressant-like effect of Valeriana glechomifolia Meyer (valerianaceae) in mice. Progress on NeuroPsychopharmacology \& Biological Psychiatry, 36: 101-109.

Neamati, A., Chaman, F., Hosseini, M., Boskabady, M.H. 2014. The effects of Valeriana officinalis L. hydro-alcoholic extract on depression like behavior in ovalbumin sensitized rats. Journal of Pharmacy and Bioallied Sciences, 6(2): 97-103.

Oliveira, D.M., Barreto, G., De Andrade, D.E.V., Saraceno, E., Aon-Bertolino, L., Capani, F., El Bacha, R.S., Giraldez, L.D. 2009. Cytoprotective effect of Valeriana officinalis extract on in vitro experimental model of
Parkinson disease. Neurochemical Research, 34: 215-220.

Pereira, R.P., Fachinetto, R., Prestes, A.S., Puntel, R.L., Silva, G.N.S., Heinzmann, B.M., Boschetti, T.K., Athayde, M.L., Burger, M.E., Morel, A.F., Morsh, V.M., Rocha, J.B.T. 2009. Antioxidant effects of different extracts from Melissa officinalis, Matricaria recutita and Cymbopogon citrates. Neurochemical Research, 34: 973-983.

Sedlak, J., Lindsay, R.H. 1968. Estimation of Total protein-bound, and nonprotein sulfhydryl groups in tissue with Ellman's reagent. Analytical Biochemistry, 25(1): 192-205.

Sudati, J.H., Fachinetto, R., Pereira R.P., Boligon, A.A., Athayde, M.L., Soares, F.A., De Vargas Barbosa, N.B., Teixeira Rocha J.B. 2009. In vitro antioxidant activity of Valeriana officinalis against different neurotoxic agents. Neurochemical Research, 34: 1372-1379.

Sung, M.N., Jung, H.C., Dae, Y.Y., Woosuk, K., Hyo, Y.J., Jong, W., Soo-Yong, K., Jaeil, P., DongWoo, K., Wan, J.K., Yeo, S.Y., In, K.H. 2013. Valeriana officinalis extract and its main component, valerenic acid, ameliorate $d$ galactose-induced reductions in memory, cell proliferation, and neuroblast differentiation by reducing corticosterone levels and lipid peroxidation. Experimental Gerontology, 48(11): 1369-1377.

Wu, J.W., Hsieh, C.L., Wang, H.Y., Chen, H.Y. 2009. Inhibitory effects of guava (Psidium guajava L.) leaf extracts and its active compounds on the glycation process of protein. Food Chemistry, 113: 78-84. 